\title{
INFLUENCE OF REAR NOZZLE ON SPRINKLER IRRIGATION UNIFORMITY
}

\author{
Wieslaw Ptach ${ }^{1}$, Stanislaw Rolbiecki ${ }^{2}$, Roman Rolbiecki ${ }^{2}$, Vilda Grybauskiene ${ }^{3}$, Barbara Jagosz ${ }^{4}$ \\ ${ }^{1}$ Warsaw University of Life Sciences, Poland; \\ ${ }^{2}$ UTP University of Science and Technology in Bydgoszcz, Poland; \\ ${ }^{3}$ Aleksandras Stulginskis University, Lithuania; \\ ${ }^{4}$ University of Agriculture in Krakow, Poland \\ wieslaw_ptach@sggw.pl,rolbs@utp.edu.pl,rolbs@utp.edu.pl,vilda.grabauskiene@asu.lt,
} b.jagosz@ogr.ur.krakow.pl

\begin{abstract}
The article presents results of researches on the influence of the rear nozzle on the sprinkler irrigation uniformity.The experimental researches were carried out in November/December 2016 at the field overgrownwith Rhodes grass (Chloris gayana), located in north-east Tanzania. Irrigation system installed on the field was based on movable Naan 5035 overhead sprinklers (plastic, impact) with six different main nozzles of sizes $(3.5,4.0,4.5,5.0,5.5,6.0 \mathrm{~mm})$ and a rear nozzle $(2.5 \mathrm{~mm})$. Sprinklerswere installed on lightweight stands of the height $1.70 \mathrm{~m}$ and spaced 15 meters. The uniformity testing consisted of a rectangular grid of collectors placed on the ground. During the experiments a total of 12 catch can tests were conducted for variants with and without the rear nozzle. The coefficient of uniformity $(C U)$ was evaluated using the Christiansen formula. During the experiments the highest $C U$ values were obtained for most variants with installed both nozzles (main and rear). Maximum value of the Christiansen coefficient of uniformity $(89.07 \%)$ was observed for $4.0 \mathrm{~mm}$ main nozzle and rear nozzle. Maximum difference of the $C U$ coefficients $(11.8 \%)$ for the variants with and without the rear nozzle was noted for the main nozzle diameter $5.0 \mathrm{~mm}$.
\end{abstract}

Keywords: irrigation uniformity, Christiansen coefficient of uniformity, sprinkler irrigation, Tanzania.

\section{Introduction}

In arid regions of the world, agriculture production often depends on irrigation. Irrigated agriculture produces $38 \%$ of the crop agricultural value in Africa from less than $6.7 \%$ of cultivated land [1]. Due to the limited resources of water the efficient use of water in African agriculture is very important. Uniform distribution of irrigation water in the root zone is one of very important parameters of the characteristic of any irrigation system. Irrigated agriculture is often criticized for its poor resource-use efficiency in the case of sprinkler systems in comparison with localized irrigation [2].Sprinklers used for irrigation of field crops usually cover circular areas. From that reason obtaining an absolutely uniform application on rectangular field area is not possible. Sprinkler water distribution pattern depends on many factors, such as: operating pressure, sprinkler type, nozzle size, number and modifications (jet-straightening vane, flow control, slot shape, etc.) [3; 4]. In field conditions, it also depends on the temperature, humidity, and wind [5-9].Based on the available information and literature search there is not yet a study or research results on the influence of the rear nozzle on the sprinkler irrigation uniformity. This publication presents some additional experimental data to know the influence of the sprinkler rear nozzle on water distribution during irrigation event.

\section{Materials and methods}

The experimental researches were carried out in November/December 2016 at the field overgrownwith Rhodes grass (Chloris gayana), it belongs to the Livestock Training Agency, located in Tengeru (north-east Tanzania). The semi-permanent irrigation system, based on hand move sprinklers, was implementedin 2010 as an element of the development project co-financed by the Ministry of Foreign Affairs of the Republic of Poland under the Polish Development Programme[10]. The Amirat irrigation system (designed by NAAN Company) installed on the field was based on movable Naan 5035 overhead sprinklers (plastic, impact). Sprinklers were installed on lightweight stands with the height $1.70 \mathrm{~m}$ and spaced 15 meters. PE section pipes (rows of three) were connected to the main PVC pipe with diameter $110 \mathrm{~mm}$ installed permanently underground. System was supplied by a diesel pump, pumping water from the nearby built small concrete reservoir. Six different main nozzles with diameters: $3.5,4.0,4.5,5.0,5.5,6.0 \mathrm{~mm}$ and a rear nozzle $(2.5 \mathrm{~mm})$ were used during the experiments and compared with the sprinklers with installed only the main nozzle. Field evaluations of sprinkler irrigation distribution were conducted adopting the methodology described in the ASAE Standard S330.1 [11] and ASAE Standard S398.1 [12]. For testing a borderline zone of the irrigated 
field was chosen. Experimental field area was limited by spacing of four sprinklers (SP1-SP4 in Fig.1) and was surrounded on 3 sides by $15 \mathrm{~m}$ spacing sprinklers. To reduce the effect of water hammer and to minimize head losses, before every irrigation event the system was vented by air valves, installed on the ends of laterals. Each irrigation experiment at this same operating pressure (350-400 kPa) lasted for 1 hour. During the experiments grass was mowed to a height of $5 \mathrm{~cm}$. The uniformity testing consisted of a rectangular grid of collectors (256 cylindrical plastic catch cans with $15 \mathrm{~cm}$ diameter and $10 \mathrm{~cm}$ height) placed on the ground (Fig. 1).After irrigation, the amounts of water collected in the catch cans were measured. The parameter used in the analysis of irrigation uniformity was the coefficient of uniformity $(C U)$.

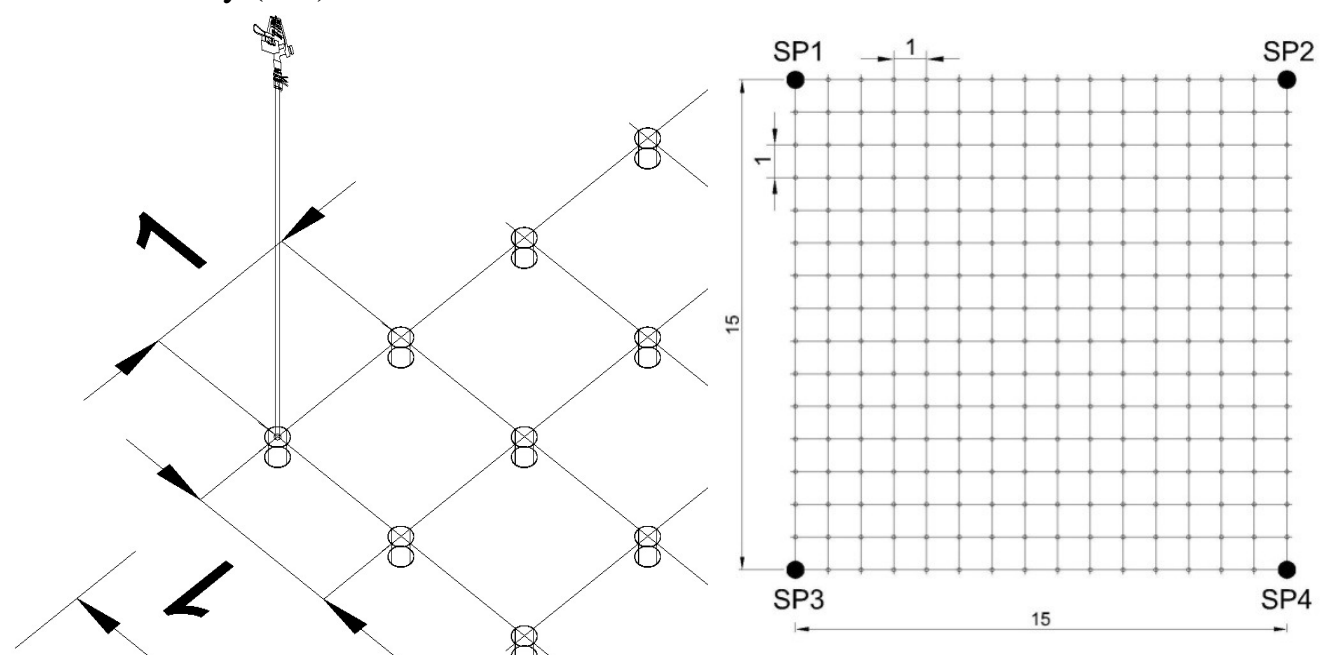

Fig. 1. Arrangement of catch-can pattern for four (SP1-SP4) sprinklers

The coefficient of uniformity $(C U)$ was evaluated using the Christiansen [13] formula:

$$
C U=100\left[1-\frac{\sum_{i=1}^{n}\left|V_{i}-V^{-}\right|}{\sum_{i=1}^{n} V_{i}}\right],
$$

where $C U-$ Christiansen uniformity coefficient;

$n$ - number of collectors used in data analysis;

$V_{i}$ - volume (or alternatively the mass or depth) of water collected in the i-th collector;

$V$ - arithmetic average volume caught by all collectors.

\section{Results and discussion}

During the experiments a total of 12 catch can tests were conducted for both sprinkler variants main nozzle with and without the rear nozzle. Fig. 2 (a-l) presents summary of the results obtained from the tests. Contour plots showing the spatial distribution of the irrigation doze were obtained using a kriging method with the Surfer software application [14]. Values of the $C U$ were calculated using the Christiansen formula. Irrigation doses presented on Fig. 2 and 3 for variants of the experiment, were calculated as a sum of quarter values of every sprinkler discharge, measured by the water meters installed on the sprinklers and divided by the experimental field area $\left(225 \mathrm{~m}^{2}\right)$.Values of the coefficient of uniformity $(\mathrm{CU})$ obtained for different variants of the experiment are compared in Fig. 4.

Coefficient of uniformity $(C U)$ for most cases of variants of irrigation realized by sprinklers with the main and rear nozzle was consistently $1 \%$ to $11.8 \%$ higher than irrigation realized by sprinklers with only the main nozzle. The maximum value of the $C U=89.07 \%$ achieved from the tests was calculated for the sprinkler with the main nozzle of diameter $4 \mathrm{~mm}$, working with the rear nozzle. The minimum value of the $C U=69 \%$ achieved from the tests was calculated for the sprinkler with the main nozzle of diameter $6 \mathrm{~mm}$, working with the rear nozzle. 

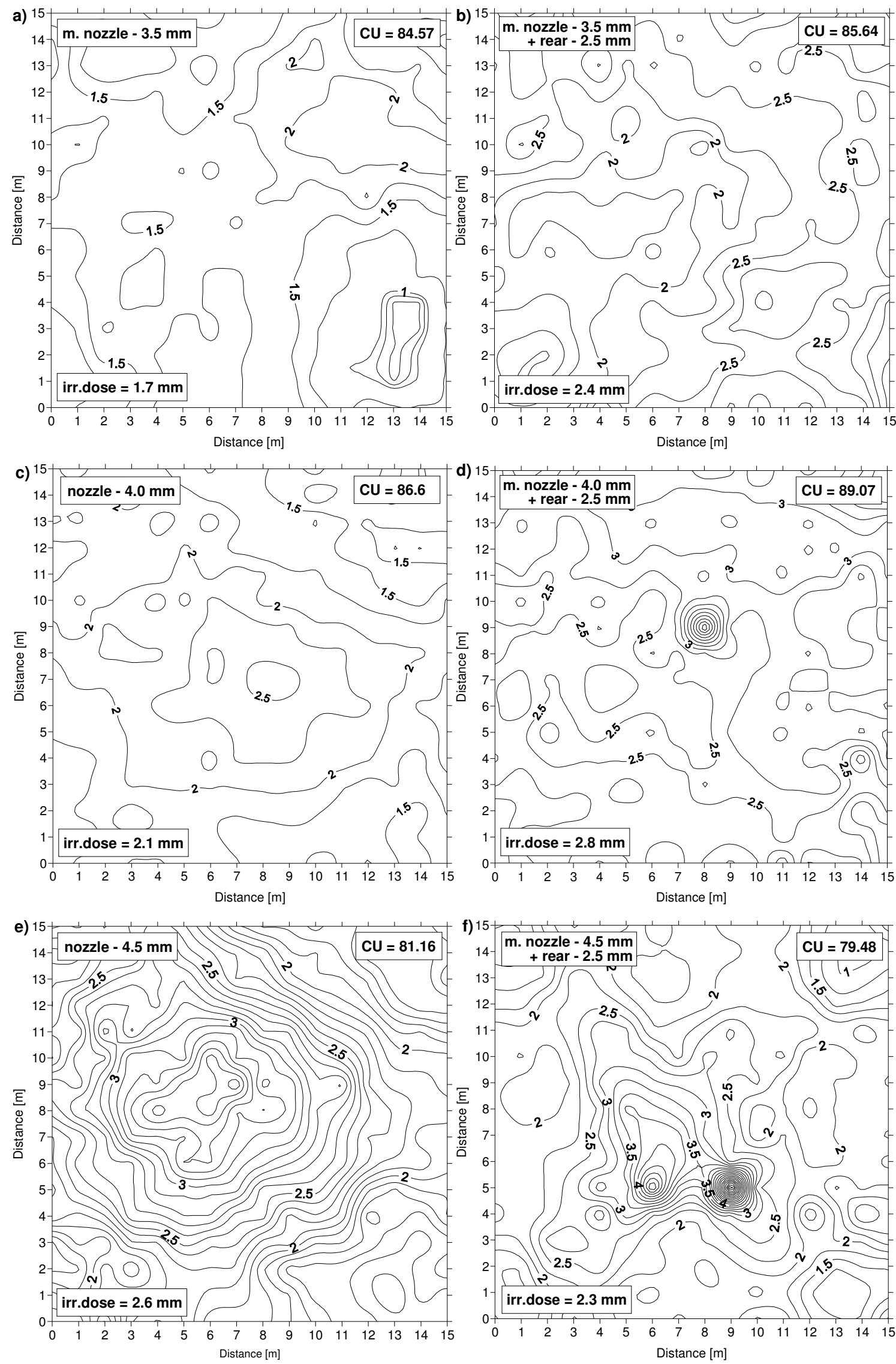

Fig. 2. Irrigation dose, Christiansen uniformity coefficient and irrigation dose distribution for sprinkler nozzles used in field experiments (part 1) 

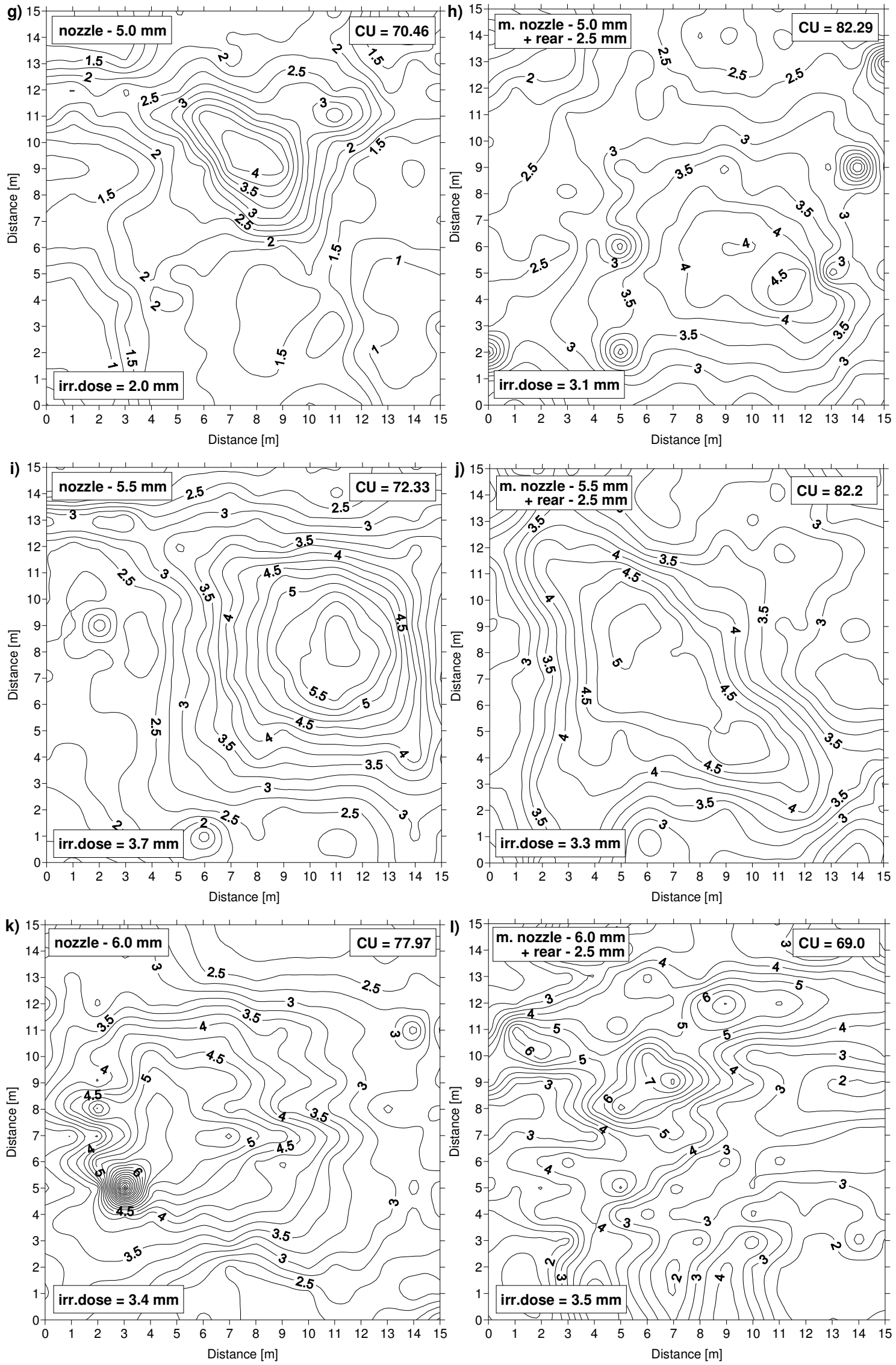

Fig. 3. Irrigation dose, Christiansen uniformity coefficient and irrigation dose distribution for sprinkler nozzles used in field experiments (part 2) 


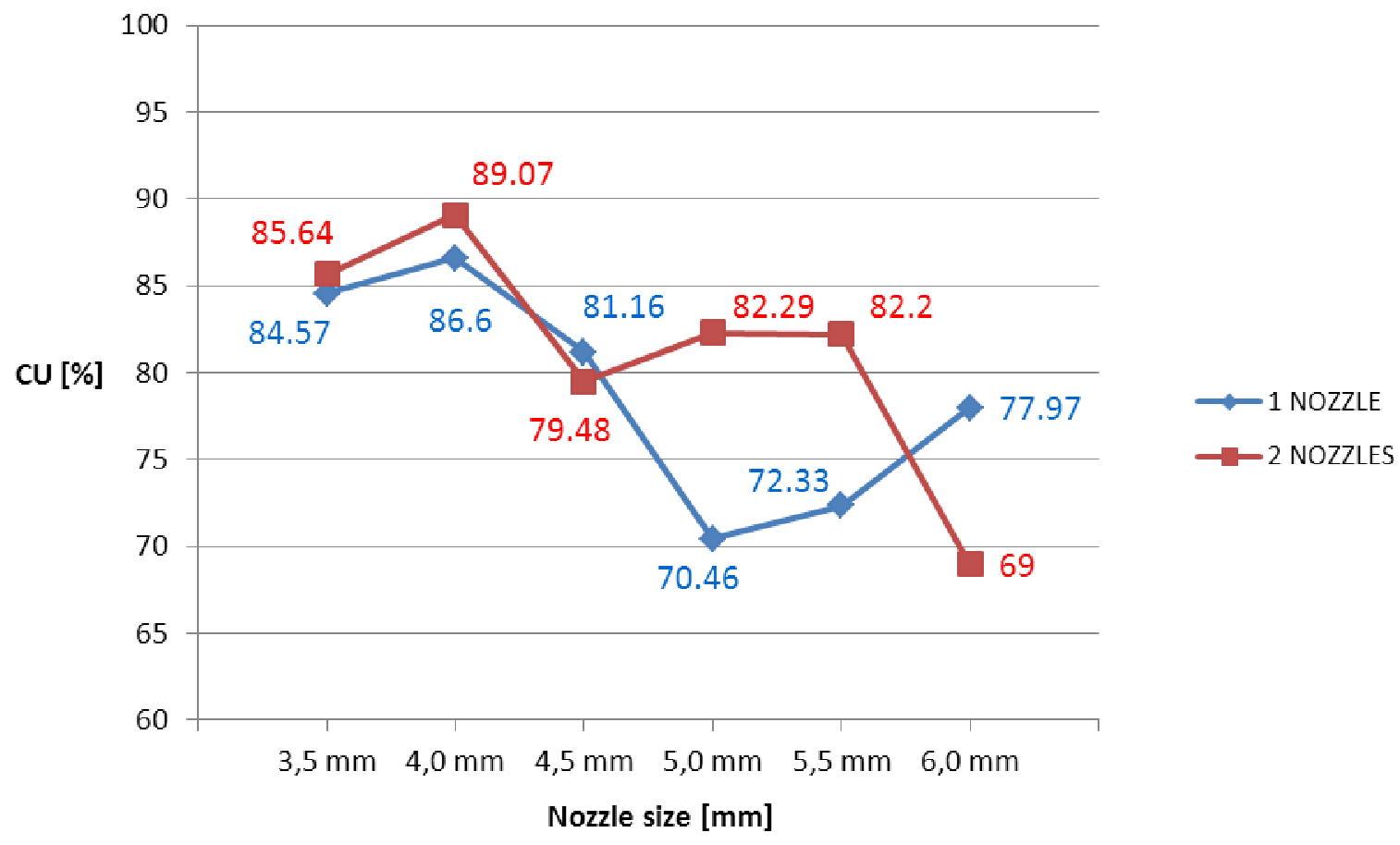

Fig. 4. Values of coefficient of uniformity $(\boldsymbol{C U})$ obtained for different variants of experiment

The mean value of the coefficient of uniformity $(81.28 \%)$ attained for the experiments with the main and rear sprinkler nozzles was higher than the mean $C U$ for the sprinklers with only the main nozzle $(78.84 \%)$.

\section{Conclusions}

1. Using a rear nozzle installed as an additive element can improve uniformity of sprinkler irrigation.

2. Coefficient of uniformity $(C U)$ used as a parameter of the analysis of irrigation uniformity was higher for the most tested variants of the sprinklers with installed main and rear nozzles than for the sprinklers with only main nozzle.

\section{Acknowledgement}

Acknowledgements are due to the Livestock Training Agency - Tengeru Director and LITA Tengeru technical staff (David Maleshi) for providing the necessary support during field researches and data collection.

\section{References}

[1] Svendsen M., Ewing M., Msangi S. Measuring irrigation performance in Africa. IFPRI Discussion Paper 00894. International Food Policy Institute. 2009.

[2] Molle B., Tomas S., Hendawi M., Granier J. Evaporation and wind drift losses during sprinkler irrigation influenced by droplet size distribution. Irrigation and Drainage, vol. 61, 2012, pp. 240-250.

[3] Junping L., Xingye Z., Shouqi Y. Theoretical and experimental study for rectangular spraying. African Journal of Agricultural Research, vol. 8, no.1, 2013, pp. 129-133.

[4] Junping L., Shouqi Y., Darko R.O. Characteristics of water and droplet size distribution from fluidic sprinklers. Irrigation and drainage, vol. 65, 2016, pp. 522-529.

[5] Dukes M.D. Effect of wind speed and pressure on linear move irrigation system uniformity. Applied Engineering in Agriculture, vol. 22, no. 4, 2006, pp. 541-548.

[6] Dwomoh F.A., Shouqi Y., Hong L. Analytical study of wind influence on in flight sprinkler droplets. Journal Eng. Technolog. Scie., vol. 47, no. 3, 2015, pp.296-305. 
[7] Kara T., Ekmekci E., Apan M. Determining of Uniformity Coefficient and water distribution characteristics of some sprinklers. Pakistan Journal of Biological Sciences, vol. 11, no.2, 2008, pp. 214-218.

[8] Lorenzini G. Air temperature effect on spray evaporation in sprinkler irrigation. Irrigation and drainage, vol. 51, 2002, pp. 301-309.

[9] Tarjuelo J.M., Montero J., Honrubia F.T., Ortiz J.J., Ortega J.F. Analysis of uniformity of sprinkle irrigation in a semi-arid area. Agricultural Water Management Vol. 40,1999, pp. 315-331.

[10] Ptach W. The implementation of irrigation system in Tanzania under development aid conditions. Infrastructure and Ecology of Rural Areas. vol. 1/III, 2013, pp.: 99-110.

[11] ASAE Standard S330.1. Procedure for sprinkler distribution testing for research purposes. In: ASAE Standards. ASAE, St. Joseph, MI. 1985.

[12] ASAE Standard S398.1. Procedure for sprinkler testing and performance reporting. In: ASAE Standards. ASAE, St. Joseph, MI. 1985.

[13] Christiansen J. E. Uniformity of application of water by sprinkler systems. Agricultural Engineering March.1941, pp. 89-92.

[14] Golden Software. Surfer ver. 5.0, Surfer Mapping System. Colorado Golden Software Inc.1994. 